\title{
Questioning What the Doctor Ordered: The Shortcomings of Defensive Medicine
}

\author{
Janelle Wen Hui Teng
}

The Hippocratic Oath speaks of good doctors being "respected by all men in all times". Unfortunately, the days of Hippocrates are long over, and so too are the golden days when a doctor's professional judgment was well-respected and deemed to be unquestionable. Malpractice litigation is ubiquitous in modern day medical practice. In America alone, there are more than 17 malpractice claims per year for every 100 full-time practicing physicians ( ). This trend is also emerging in Asian countries, such as in Singapore where there was a 90\% increase in malpractice claims in 2010 as compared to 2006 ( ). The increasing risk of malpractice liability and fear of devastating economic and professional ramifications have led more doctors to practice defensive medicine as a pre-emptive measure. Defensive medicine, broadly defined as medical practices undertaken primarily due to concern about malpractice liability, may be manifested as assurance behaviors which have marginal added value, such as the ordering of additional tests or overprescribing of unnecessary medicines; or as avoidance behaviors, whereby a doctor avoids high-risk patients and procedures ( ).

A staggering $83 \%$ to $93 \%$ of doctors surveyed have admitted to practicing defensively (3- ). The pervasiveness of this phenomenon has impacted different stakeholders in various ways. Ostensibly, from the patients' viewpoint, defensive medicine acts positively as a deterrent against poor-quality care, and helps to reduce tolerance for medical ambiguity. However, a more detailed analysis reveals many negative repercussions of

\footnotetext{
*To whom correspondence should be addressed:

Janelle Teng

531 Lasuen Mall

P.O. Box 11092

Stanford, CA 94309, USA

Tel: (+1) 443-799-0876

Email: janelleteng@stanford.edu
}

defensive medicine on healthcare quality. Firstly, patients experience reduced access to care. For instance, while practicing defensively, some family physicians in Florida, Mississippi, Texas and Pennsylvania have stopped offering obstetrics services ( ). Secondly, while defensive practices result in precious resources being wasted on some patients, other patients who genuinely require care, such as the critically ill, are deprived of urgent attention as they contend with long lines, fully-occupied machines and overworked healthcare workers ( ). Thirdly, defensive medicine may delay the adoption of new medical innovations in patient treatment. A study found that $53 \%$ of physicians were not keen to implement new technologies due to conscious concern over potential liability ( ). Lastly, even the apparent benefits of defensive medicine can become detrimental. For example, doctors tend to be overly cautious when interpreting mammograms as failure to diagnose breast cancer is a common malpractice allegation. This leads to more false-positive results, which not only increase healthcare costs by $33 \%$, but also cause unnecessary stress to both patient and doctor (1).

Defensive practices also subject patients to additional risks and can worsen their clinical outcomes. Studies have shown that there is a substantial risk of cancer development due to radiation overexposure from defensive CT scan ( ). Additionally, the overuse of antibiotics stemming from defensive medicine could result in the emergence of a multi-drug resistant superbug which could threaten mankind's survival ( ).

From an economic perspective, defensive medicine inflates healthcare costs on many micro and macro levels. Doctors ordering panels of additional or clinically-unwarranted tests ultimately translate into a greater financial burden for patients ( ). In one case, a patient with a stomach ache was sent immediately for a US\$6,500 CT scan ( ). 
She was subsequently found to be suffering from a harmless ovarian cyst, which could have been easily detected if a US $\$ 1,400$ ultrasound had been ordered initially based on her symptoms. Approximately $25 \%$ of annual healthcare costs in America is wasted on unnecessary defensive procedures (7). The estimated annual cost of defensive Cesarean Sections ranges from US $\$ 8.7$ million to over US $\$ 5$ billion; and the annual cost of defensive radiologic procedures for young emergency room patients is approximately US $\$ 45$ million $(7$, ). Collectively, annual estimated defensive medicine costs in America range from US $\$ 50$ billion to US $\$ 850$ billion $(7,-)$.

Ultimately, defensive medicine does not augur well for the future of the medical community. It places a huge strain on the doctor-patient relationship. $71 \%$ of doctors surveyed felt that practicing defensive medicine caused them to view their patients in a negative light (7). Whilst practicing defensively, doctors also divert much of their focus to filling up paperwork to document their actions, which detracts from their time spent with patients (6). Defensive medicine shifts the practice of medicine from being patient-centered to being test-centered, causing doctors to rely on tests to rule out ailments, rather than focusing on the patient's concerns. This longterm reliance on tests for diagnosis may reduce the astuteness of some doctors, and $57 \%$ claim that defensive medicine hampers their professional decision-making ability (7). Another dire concern is that defensive medicine may deter individuals from entering the medical profession, thereby exacerbating the shortage of doctors in certain countries (7).

Despite being a common practice, defensive medicine should not be passively accepted as an inevitable component of the healthcare industry. Some countries have implemented traditional tort reforms, such as reducing the statute of limitations, as a means to protect doctors from litigation (13). Society should also focus on eliminating defensive medical practices through the establishment of an explicit legal standard of basic medical care using clear practice guidelines. Such a standard could be built upon the tenets of the Bolitho and Bolam Tests, where a doctor's actions are in accordance with a responsible body of medical opinion and can withstand logical analysis and scrutiny.

\section{REFERENCES}

1. Anderson RE. Billions for defense: the pervasive nature of defensive medicine. Arch Intern Med. 1999 Nov;159(20):2399-402.

2. Khalik S. Rise in claims against doctors here. The Straits Times. 2011 Aug 8:Sect. A:1.
3. Studdert DM, Mello MM, Sage WM, DesRoches CM, Peugh J, Zapert K, Brennan TA. Defensive medicine among high-risk specialist physicians in a volatile malpractice environment. JAMA. 2005 Jun 1;293(21):2609-17.

4. Massachusetts Medical Society. Investigation of Defensive Medicine in Massachusetts. Waltham, MA: Massachusetts Medical Society; 2008 Nov.

5. Kavaler F, Spiegel AD. Risk Management in Health Care Institutions: A Strategic Approach, Second Edition. Sudbury, MA: Jones \& Bartlett Publishers;2003.

6. Fodeman JD. Defensive medicine costs. The Washington Times [Internet]. 2009 Nov 29 [cited 2011 Jul 31]. Available from: http://www.washingtontimes.com/news/2009/nov/29/ defensive-medicine-costs/.

7. Jackson Healthcare. A Costly Defense: Physicians Sound Off on the High Price of Defensive Medicine in the U.S. [monograph online]. Atlanta, GA: Jackson Healthcare; 2010 [cited 2011 July 31]. Available from: http://www.jacksonhealthcare.com/media/91481/defensivemedicine_ebk0610c.pdf.

8. DeKay ML, Asch DA. Is the defensive use of diagnostic tests good for patients, or bad?. Med Decis Making. 1998 Jan-Mar;18(1):19-28.

9. Winslow JE, Hinshaw JW, Hughes MJ, Williams RC, Bozeman WP. Quantitative assessment of diagnostic radiation doses in adult blunt trauma patients. Ann Emerg Med. 2008 Aug;52(2):93-7.

10. Overdoing antibiotics. Harv Health Lett. 2002 Nov;28(1):45.

11. U.S. Department of Health \& Human Services. Addressing the New Health Care Crisis: Reforming the Medical Litigation System to Improve the Quality of Health Care. March 2003. Washington, DC: Prepared by the Office of the Assistant Secretary for Planning and Evaluation, U.S. Department of Health and Human Services, March 3, 2003.

12. Defensive Medicine: Cautious Or Costly? [television broadcast]. CBS News. Richmond, Virginia: CBS; 2007 Oct 22.

13. U.S. Congress, Office of Technology Assessment. Defensive Medicine and Medical Malpractice, OTA-H--6O2. Washington, DC: U.S. Government Printing Office; 1994 July.

14. Mello M, Chandra A, Gawande A, Studdert D. National Costs of the Medical Liability System. Health Aff. 2010 Sep;29(9):1569-77.

15. Kessler D, McClellan M. Do Doctors Practice Defensive Medicine? Q J Econ. 1996;111(2):353-90. 